\title{
Remembering People: Neuroimaging Takes On the Real World
}

\author{
Paul J. Whalen \\ Departments of Psychiatry and Psychology, University of Wisconsin-Madison, Madison, Wisconsin 53705, USA
}

There he is. You met him not four months ago at a function just like this. You recognize the face. But his name ... what is his name?! Suddenly, he is upon you, remembering your name with ease. "Heeeeeeyyyyyy!" is all you can muster. This elongated greeting serves two vital purposes. First, it's a time-killer. You could still remember the name. Second, it is intended to communicate a level of familiarity, suggesting that your relationship has reached the point that transcends the use of names. He's not buying it. After some uncomfortable banter, the acquaintance bids your squirming, embarrassed self good-bye. You've done it again, Sherlock.

The study of memory is nuanced and ever evolving, but if there is one truth within the greater field, it is this: Effective explicit recall depends upon proper elaborative encoding. Unless a name is actively rehearsed or a mnemonic strategy is invoked, recall is likely to be poor. For example, I once had the greatest difficulty remembering the name of a woman I had met named Gisa, until it later occurred to me that her name rhymed with both a leaning tower and a credit card.

When we meet someone for the first time, other thoughts likely impede our ability to invoke such strategies. We may be busy assessing the other person's style of dress. Maybe they resemble someone else we know. Perhaps we are wondering what they think of us. These processes effectively comprise "distractor tasks" serving to hinder the proper encoding of the one bit of information that we must come away with-the name. Here, a very simple task becomes an all too common social faux pas. Our brains, as impressive as they are, are often no match for the social contexts in which they find themselves.

In this issue, Paller and colleagues (Paller et al. 2003) offer human neuroimaging data identifying neural circuits involved when subjects explicitly attempted to remember biographical information (including names) related to pictures of faces they had previously seen. Subjects in this study were shown numerous pictures of faces. During presentation of a subset of these faces, subjects also heard a voice describing the name and a biographical detail of the presented face. Subjects were scanned during subsequent presentations of these faces (this time, no auditory biographical information was presented) and told to retrieve this information for the relevant subset of faces. Most notably, this paper reports that retrieval of this biographical information was related to activation of the medial temporal lobe, including convincing involvement of the hippocampus. In addition, the authors present a parallel ERP study that offers data concerning the timing of brain responses associated with this task. These data, together with other studies in which subjects were presented with face-name pairs (Campanella et al. 2001; Sperling et al. 2001), provide an important starting point for the study of this very human ability. In addition, the present study also reports involvement of the prefrontal cortex, suggesting that these data may also be relevant to more basic human studies of source

E-MAIL pwhalen@wisc.edu; FAX (608) 262-9440.

Article and publication are at http://www.learnmem.org/cgi/doi/10.1101/ Im.65003. memory (see, e.g., Dobbins et al. 2002), that is, the recall of contextual details associated with a previously encountered stimulus (see recommended reading in Box 1).

As with any interesting initial study, there is, of course, more that we would like to know. For example, because subjects covertly retrieved biographical information during scanning, we cannot know with absolute certainty which activations presented here are related to the explicit retrieval of this information. Indeed, subjects knew they would have to provide this information again (following scanning), and it is therefore likely that there were both explicit retrieval and re-encoding processes ongoing during the scanning phase. Such questions can be addressed in future studies. And, as the authors note, the parallel ERP study data closely resemble other work from this laboratory assessing retrieval processes.

A novel and important aspect of this study is the ecologically valid means by which biographical information was provided to subjects. In social situations we are often simultaneously presented with a visual facial stimulus and auditory biographical information. The present study cleverly provides stimulus information in an experimental fashion that reasonably approximates these conditions. Future studies could move further in this direction by introducing competing tasks that might mimic some of the real-life distractors described above.

Experimental studies are also hard pressed to match the motivations of their subjects with those that propel these real-life scenarios. For example, very different motivations likely underlie our desire to remember people in the first place. The present study used a monetary incentive to ensure behavioral compliance. Although we again could question the ecological validity of this, we can acknowledge that we often find ourselves at social engagements with only external motivation to actually encode and retrieve biographical information of the people we meet. (For example, imagine being at an office party of a significant other, where the pressure to meet and remember people comes solely from the wishes of the significant other.)

It is, of course, impossible to know what the exact relevance is of brain activations in memory studies of this sort to the human examples of social interaction I have provided here. Indeed,

\section{Recommended Reading}

Buckner, R.L. and Wheeler, M.E. 2001. The cognitive neuroscience of remembering. Nat. Reviews Neurosci. 2: 624-634.

Dobbins, I.G., Foley, H., Schacter, D.L., and Wagner, A.D. 2002. Executive control during episodic retrieval: Multiple prefrontal processes subserve source memory. Neuron 35: 989-996.

Savage, C.R., Deckersbach, T., Heckers, S., Wagner, A.D., Schacter, D.L., Alpert, N.M., Fischman, A.J., and Rauch, S.L. 2001 Prefrontal regions supporting spontaneous and directed application of verbal learning strategies: Evidence from PET. Brain 124: 219-231.

Shimamura, A.P., Janowsky, J.S., and Squire, L.R. 1991. What is the role of frontal lobe damage in memory disorders? In Frontal lobe function and dysfunction (eds. H.S. Levin et al.), pp. 173-195. Oxford University Press, New York. 
ecological validity is particularly difficult to achieve in neuroimaging studies, given the supine position and confined context in which the subjects find themselves (although I can think of social engagements in which I have felt like this). The present study offers one example of a strategy for making these studies at least more ecologically valid. The point is not whether any one study has achieved true ecological validity, but that these truly human examples of behavioral interaction drive this work in the first place. We can concede that behavioral science cannot mirror human experience, yet still look forward to the possibility that certain findings will allow us to "see" a bit of ourselves a little more clearly.

\section{REFERENCES}

Campanella, S., Joassin, F., Rossion, B., DeVolder, A., Bruyer, R., and Crommelinck, M. 2001. Association of the distinct visual representations of faces and names: A PET activation study. NeuroImage 14: 873-882.

Dobbins, I.G., Foley, H., Schacter, D.L., and Wagner, A.D. 2002. Executive control during episodic retrieval: Multiple prefrontal processes subserve source memory. Neuron 35: 989-996.

Paller, K., Ranganath, C., Gonsalves, B., LaBar, K.S., Parrish, T.B. Gitelman, D.R., Mesulam M.-M., and Reber, P.J. 2003. Neural correlates of person recognition. Learn. Mem. 10: (this issue).

Sperling, R.A., Bates, J.F., Cochiarella, A.J., Schacter, D.L., Rosen, B.R., and Albert, M.S. 2001. Encoding novel face-name associations: A functional MRI study. Hum. Brain Mapp. 14: 129-139. 


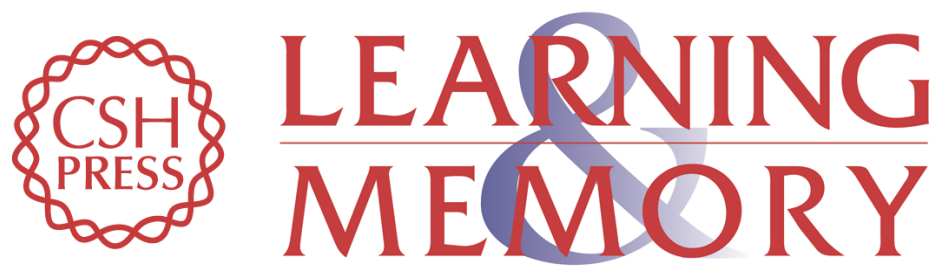

\section{Remembering People: Neuroimaging Takes On the Real World}

Paul J. Whalen

Learn. Mem. 2003, 10:

Access the most recent version at doi:10.1101//m.65003

\section{License}

Email Alerting Receive free email alerts when new articles cite this article - sign up in the box at the Service top right corner of the article or click here. 